\title{
Anti-Tissue Factor Monoclonal Antibody MORAb-066
}

National Cancer Institute

\section{Source}

National Cancer Institute. Anti-Tissue Factor Monoclonal Antibody MORAb-066. NCI

Thesaurus. Code C104291.

A humanized monoclonal antibody against human tissue factor (TF), with potential antiangiog enic, anticoagulant and anti-inflammatory activities. Upon administration, antiTF monoclonal antibody MORAb-066 binds to TF and prevents Factor VIIa (FVIIa) from binding, thereby interfering with the activation of Factor X (FX) into FXa. This may prevent thrombin formation and cancer-associated venous thromboembolism, and may inhibit angiogenesis and tumor cell proliferation. TF, a transmembrane protein and initiator of the coagulation cascade, is overexpressed in many tumor cells and tumor endothelial cells; its expression is correlated with metastasis, ang iog enesis, tumor cell growth and tumor-associated thrombosis. 